\title{
Benzodiazepine receptor antagonist (flumazenil) does not affect sleep-related breathing disorders
}

\author{
B. Schönhofer, D. Köhler
}

\begin{abstract}
Benzodiazepine receptor antagonist (flumazenil) does not affect sleep-related breathing disorders. B. Schönhofer, D. Köhler. (C)ERS Journals Ltd 1996.

ABSTRACT: Benzodiazepine drugs may impair breathing during sleep, leading to the development of sleep-disordered breathing or, in subjects with sleep apnoea, an increase in the severity of pre-existing apnoeas. Flumazenil is a selective benzodiazepine-antagonist. We hypothesized that endogenous ligands of benzodiazepine receptors might contribute to the pathogenesis of obstructive sleep apnoea syndrome (OSAS) and that the intensity of OSAS could, therefore, be reduced by flumazenil.

Ten male patients (mean age $55 \mathrm{yrs}$, mean body mass index $42.4 \mathrm{~kg} \cdot \mathrm{m}^{-2}$, mean apnoea index (AI) 53.5 and mean respiratory disturbance index (RDI) 74.2) were investigated. None of the patients had been treated for OSAS prior to the study. The study design was randomized, single-blind, placebo-controlled and cross-over. On the first or second study night, patients were randomly assigned to receive $i$.v. flumazenil $(2 \mathrm{mg})$ or placebo $(0.9 \% \mathrm{NaCl})$ between $01: 00$ and $01: 30 \mathrm{~h}$.

Comparing the polysomnographic results of the placebo night and the flumazenil night in all 10 patients, no significant differences were found regarding obstructive events or sleep architecture. Accordingly, the data concerning sleep-disordered breathing and sleep stages during the $30 \mathrm{~min}$ period prior to and the $\mathbf{3 0} \mathrm{min}$ period following the administration of flumazenil did not differ.

It is concluded that endogenous ligands of the benzodiazepine receptor play no role in the pathogenesis of obstructive sleep apnoea syndrome, since respiratory and sleep data are not altered by flumazenil. Therefore, attempts to treat obstructive sleep apnoea syndrome with flumazenil do not seem to be warranted. Eur Respir J., 1996, 9, 1816-1820.
\end{abstract}

Krankenhaus Kloster Grafschaft, Zentrum für Pneumologie und Allergologie, Schmallenberg-Grafschaft, Germany.

Correspondence: B. Schönhofer Krankenhaus Kloster Grafschaft Zentrum für Pneumologie und Allergologie D-57392 Schmallenberg-Grafschaft Germany

Keywords: Benzodiazepine antagonist endogenous benzodiazepines flumazenil

obstructive sleep apnoea

Received: June 61995

Accepted after revision April 251996
Obstructive sleep apnoea syndrome (OSAS) is characterized by recurrent interruptions of airflow during sleep due to upper airway obstruction. The pathophysiology of these obstructive events is multifactorial, including an increased collapsibility of the soft tissues of the pharynx and decreased pharyngeal patency, especially during sleep [1].

Centrally-acting depressants may influence breathing in sleep by several mechanisms. These include: altered upper airway tone; modification of chemoreceptor function [2]; or changes in arousability to respiratory stimuli. Like ethanol, the central nervous system pharmacological actions of benzodiazepines are mediated via an interaction with the gamma-aminobutyric acid (GABA)-BDZ receptor complex [3, 4]. Ethanol intake selectively decreases genioglossal muscle activity, impairing the upper airway stability $[3,5]$. The existing literature regarding the effects of benzodiazepines on sleep-related breathing disorders (SRBD) is conflicting. Although several authors have reported worsening of sleep apnoea after administration of benzodiazepines [6-8], other authors have found little or no influence on the severity of SRBD [9-10]. Apart from influencing respiration during sleep, the effects of benzodiazepines include: sedation; anxiolysis; sleep induction; and an anticonvulsive action.
The existence of the benzodiazepine receptor has raised the possibility of endogenous ligands linked to GABA neurotransmission. The findings that exogenous benzodiazepines may lead to the development of, or an increase in the pre-existing sleep apnoea [6-8] has led us to the hypothesis that endogenous benzodiazepines (increased GABA-ergic tone) may contribute to the pathogenesis of OSAS.

Flumazenil has been developed as a selective antagonist of the benzodiazepine receptor subunit of the GABA receptor complex $[11,12]$. It antagonizes the neurological and electrophysiological effects of active benzodiazepines on the central nervous system, such as muscle relaxation, sedation and depression of breathing $[12,13]$. Flumazenil is a water soluble imidazo-benzodiazepine. It is administered intravenously. After administration, flumazenil displaces benzodiazepine derivates completely from the benzodiazepine receptor subunit of the GABA receptor complex [12]. The onset of the antagonistic effect is measurable within 30-120 s after injection, with a half-life in plasma of approximately $50 \mathrm{~min}$. The physiological duration of the effect is $2-3 \mathrm{~h}$. Flumazenil is metabolized by the liver [14].

If our hypothesis that endogenous benzodiazepines contribute to the pathogenesis of OSAS was correct, then 
this finding suggested that a benzodiazepine receptor antagonist, such as flumazenil, would have a potential role in the management of OSAS. Therefore, to examine possible pathophysiological and therapeutic implications, we performed a placebo-controlled, single-blind, cross-over polysomnographic study with flumazenil in patients with severe OSAS.

\section{Material and methods}

\section{Subjects}

Ten consecutive male patients (aged $55 \pm 8$ yrs (mean \pm $\mathrm{SD}$ ), body mass index $42.4 \pm 5.3 \mathrm{~kg} \cdot \mathrm{m}^{-2}$ ) were recruited. All patients who were enrolled in the study had OSAS with an apnoea index (AI) of more than 40, diagnosed using a polygraphic screening method (Poly G; CNS, Minneapolis, USA). None of the patients had been treated for their OSAS prior to the present study. Pulmonary function tests and arterial blood gas measurements were normal in all patients. Patients with a history of seizure, arrhythmia, impaired renal or hepatic function, and patients taking medication with effects on the central nervous system were excluded from the study. Written and oral consent to the study protocol was obtained from all patients.

\section{Polysomnographic study}

Polysomnographic recordings were obtained with the CNS-sleep laboratory system (Minneapolis, 8-channel) and consisted of 2 electroencephalogram (EEG) leads (C4$\mathrm{A} 1$ and C3-A2 derivations), electro-oculogram (EOG), electromyogram (EMG) of submental and tibialis anterior muscles, and electrocardiogram (ECG). Respiration was monitored using oronasal thermistors, thoracic and abdominal movements (inductive plethysmography). The body position was verified by infrared video recording and a position detector. The transcutaneous arterial oxygen saturation $\left(\mathrm{Sa}_{\mathrm{a}} \mathrm{O}_{2}\right)$, using finger pulse-oximetry (Pulsox 7; AVL, Minolta, D-Bad Homburg) was also recorded. The manual scoring of the raw data was performed for all periods. Sleep stages were scored according to the criteria of RECHTSCHAFFEN and KALES [15]. This made it possible to determine the total sleep time (TST), defined as total study time from lights off to lights on minus awake periods. Sleep efficiency was determined as the TST divided by the total time in bed. Sleep latency was defined as the time from the start of the study to sleep onset. Arousals were scored according to the American Sleep Disorders Association criteria [16].

\section{Definitions}

Apnoea was defined as a cessation of airflow both at the mouth and nose for at least $10 \mathrm{~s}$. When thoracic and abdominal movements were present, apnoeas were classified as obstructive. A central apnoea was scored when these movements were absent. Hypopnoea was defined as a reduction in airflow with a 50\% reduction in tho- racic and abdominal efforts and a 4\% drop in oxygen saturation for at least $10 \mathrm{~s}$. False positive hypopnoeas due to changing posture were excluded by means of a body position sensor and the infrared video recording. Indices of SRBD were calculated, including apnoea index (AI) (the number of apnoeas divided by TST in minutes and expressed as events $\cdot \mathrm{h}^{-1}$ ) and the respiratory disturbance index (RDI) (the sum of the observed apnoeas and hypopnoeas divided by the TST in minutes and expressed as events $\left.\cdot h^{-1}\right)$. The arousal index (ArI) is defined as the number of arousals $\cdot \mathrm{h}^{-1}$ of sleep. The duration of each respiratory event, the oxygen desaturation that occurred with each event, and the lowest oxygen saturation for each event were calculated and recorded.

\section{Study protocol}

Each experiment was preceded by an adaptation night in the sleep laboratory, during which no recordings were made. On the diagnostic night and the following two experimental nights, sleep studies were performed using standard polysomnography. On the first or second study night, patients were randomly assigned to receive flumazenil or placebo $(0.9 \% \mathrm{NaCl})$ in a cross-over, patientblinded design. The total amount of $2 \mathrm{mg}$ flumazenil or placebo $(20 \mathrm{ml} 0.9 \% \mathrm{NaCl})$ was injected between 01:00 and $01: 30 \mathrm{~h}$. The mode of injection followed that described previously [17]: i.v. bolus of $0.3 \mathrm{mg}$ flumazenil followed by $0.1 \mathrm{mg} \cdot \mathrm{min}^{-1}$.

\section{Data analysis and statistics}

Respiratory and sleep parameters were compared between the two experimental nights. Additionally, because

Table 1. - Anthropometric data of the 10 male patients and results of the whole night diagnostic sleep study

\begin{tabular}{|c|c|}
\hline Age yrs & $55 \pm 8$ \\
\hline $\mathrm{BMI} \mathrm{kg} \cdot \mathrm{m}^{-2}$ & $42.4 \pm 5.3$ \\
\hline AI events $\cdot \mathrm{h}^{-1}$ & $53.5 \pm 11.4$ \\
\hline RDI events $\cdot h^{-1}$ & $74.2 \pm 13.6$ \\
\hline Mean nocturnal $\mathrm{Sa}_{\mathrm{a}, \mathrm{O}_{2}} \%$ & $80 \pm 5$ \\
\hline Minimum $\mathrm{Sa}_{\mathrm{a}, \mathrm{O}_{2}} \%$ & $57 \pm 13$ \\
\hline Mean event duration $\mathrm{s}$ & $21.5 \pm 4.3$ \\
\hline Maximum event duration $\mathrm{s}$ & $54.7 \pm 13.2$ \\
\hline \multicolumn{2}{|l|}{ Body position \% } \\
\hline Left & $26 \pm 14$ \\
\hline Right & $35 \pm 12$ \\
\hline Back & $32 \pm 10$ \\
\hline Prone & $6 \pm 8$ \\
\hline Position changing $\mathrm{n} \cdot \mathrm{h}^{-1}$ & $3.9 \pm 3.1$ \\
\hline TST min & $349 \pm 13$ \\
\hline SE \% & $92 \pm 2$ \\
\hline $\mathrm{SL} \min$ & $8.6 \pm 2.1$ \\
\hline REM \% & $6 \pm 5$ \\
\hline Stage 1-2 NREM \% & $87 \pm 5$ \\
\hline Stage 3-4 NREM \% & $7 \pm 6$ \\
\hline ArI $n \cdot h^{-1}$ & $73.9 \pm 14.3$ \\
\hline
\end{tabular}

Values are presented as mean \pm SD. BMI: body mass index; AI: apnoea index; RDI: respiratory disturbance index; $\mathrm{Sa}_{\mathrm{a}} \mathrm{O}_{2}$ : arterial oxygen saturation; TST: total sleep time; SE: sleep efficiency; SL: sleep latency; REM: rapid eye movement sleep; NREM: non-rapid eye movement sleep; ArI: arousal index. 


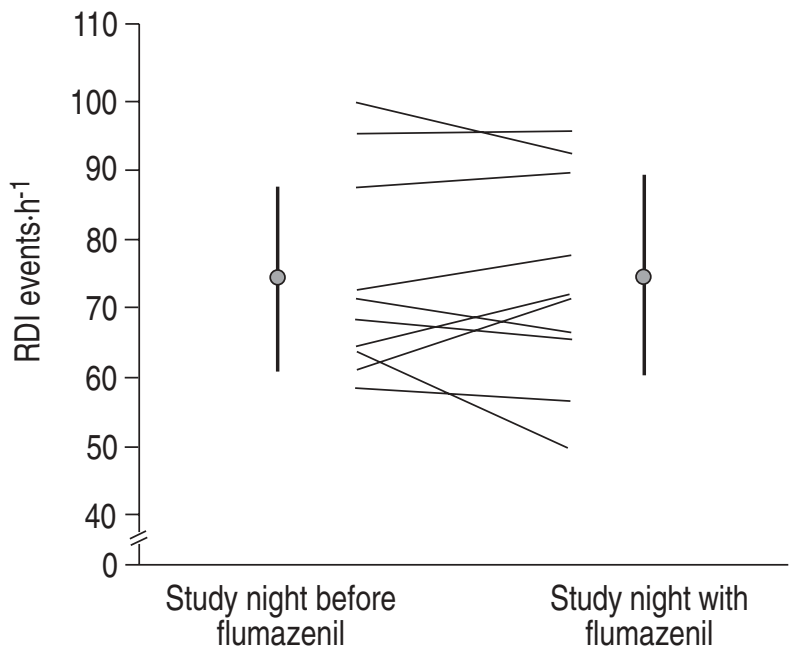

Fig. 1. - Individual respiratory disturbance index (RDI) during the placebo and the flumazenil night. The vertical bars represent mean \pm SD for each night.

Table 2. - Comparison of the sleep study results of the placebo $(0.9 \% \mathrm{NaCl})$ and flumazenil night

\begin{tabular}{|c|c|c|c|}
\hline & $\begin{array}{l}0.9 \% \\
\mathrm{NaCl}\end{array}$ & $\begin{array}{l}2 \mathrm{mg} \\
\text { flumazenil }\end{array}$ & $\mathrm{p}$-value \\
\hline AI events $\cdot h^{-1}$ & $54.2 \pm 13.4$ & $58.7 \pm 16.5$ & NS \\
\hline RDI events $\cdot h^{-1}$ & $74.2 \pm 13.6$ & $73.9 \pm 14.8$ & NS \\
\hline Mean $\mathrm{S}_{\mathrm{a}, \mathrm{O}_{2}} \%$ & $80 \pm 5$ & $82 \pm 4$ & NS \\
\hline Minimum $\mathrm{S}_{\mathrm{a}, \mathrm{O}_{2}} \%$ & $57 \pm 13$ & $59 \pm 12$ & NS \\
\hline Mean $\mathrm{A} / \mathrm{H}$ duration & $21.4 \pm 4.3$ & $23.3 \pm 5.7$ & NS \\
\hline Maximal $\mathrm{A} / \mathrm{H}$ duration & $58.3 \pm 17.9$ & $60.4 \pm 30.5$ & NS \\
\hline \multicolumn{4}{|l|}{ Body position \% } \\
\hline Left & $25 \pm 12$ & $28 \pm 17$ & NS \\
\hline Right & $33 \pm 15$ & $36 \pm 13$ & NS \\
\hline Back & $35 \pm 6$ & $32 \pm 10$ & NS \\
\hline Prone & $6 \pm 10$ & $5 \pm 8$ & NS \\
\hline $\begin{array}{l}\text { Changing body position } \\
\mathrm{n} \cdot \mathrm{h}^{-1}\end{array}$ & $3.6 \pm 3.9$ & $3.9 \pm 2.3$ & NS \\
\hline TST min & $352 \pm 18$ & $354 \pm 21$ & NS \\
\hline SE \% & $93 \pm 3$ & $92 \pm 2$ & NS \\
\hline SL $\min$ & $7.5 \pm 1.5$ & $8.5 \pm 2.5$ & NS \\
\hline REM \% & $7 \pm 3$ & $7 \pm 5$ & NS \\
\hline Stage 1-2 NREM \% & $85 \pm 6$ & $85 \pm 7$ & NS \\
\hline Stage 3-4 NREM \% & $8 \pm 4$ & $8 \pm 5$ & NS \\
\hline ArI $n \cdot h^{-1}$ & $73.2 \pm 11.5$ & $74.6 \pm 15.3$ & NS \\
\hline
\end{tabular}

Values are presented as mean \pm SD. NS: nonsignificant; A/H: apnoea/hypopnoea events. For further definitions see legend to table 1 . of the fast onset of action of flumazenil, the characteristics of the respiratory events, sleep stages, body position and arousals during sleep were also compared for the $30 \mathrm{~min}$ period prior to injection of flumazenil with the $30 \mathrm{~min}$ postadministration period. In order to present a full polysomnographic analysis, sleep latency was measured in the baseline polysomnography and dropped on the study nights, since the drug was given whilst the patients slept. Results were expressed as mean \pm SD. The Wilcoxon signed-rank matched pairs test for nonparametric paired data was used for the statistical comparison. A p-value lower than 0.05 was considered to be significant.

\section{Results}

The baseline results for respiratory data (RDI, AI, mean nocturnal desaturation, minimum oxygen saturation, mean event duration, maximum event duration) and sleep data (TST, SE, sleep latency, sleep stages, ArI and body position) are presented in table 1 . No significant differences were found comparing the polysomnographic results of the night with and without flumazenil in all 10 patients. The data concerning SRBD and body position did not differ significantly after administration of flumazenil (fig. 1 and table 2). Correspondingly, the TST, SE, sleep stages and the frequency of arousals remained unchanged during the study nights (table 2). The polysomnographic data during the $30 \mathrm{~min}$ period prior to and the 30 min period immediately following the administration of flumazenil did not differ (table 3 and fig. 2). Flumazenil did not lead to any alteration of the SRBD, nor did it modify the subjects sleep stages. Furthermore, the frequency of arousals, awakenings and changes in the body position were not different during the $30 \mathrm{~min}$ after flumazenil injection compared to the $30 \mathrm{~min}$ before (table 3 ).

\section{Discussion}

This study aimed to examine whether GABA-mediated inhibitory neurotransmission is either a cause of OSAS or contributes to its severity. Because the actions of flumazenil, in the usual dose range, are strongly related to its ability to bind to benzodiazepine receptors on the GABABDZ receptor complex, we hypothesized that an increased

Table 3. - Comparison of the sleep study results of the $30 \mathrm{~min}$ before and $30 \mathrm{~min}$ after the injection of flumazenil or placebo

\begin{tabular}{|c|c|c|c|c|c|c|}
\hline & \multicolumn{3}{|c|}{$0.9 \% \mathrm{NaCl}$} & \multicolumn{3}{|c|}{ 2mg Flumazenil } \\
\hline & $30 \mathrm{~min}$ before & $30 \mathrm{~min}$ after & p-value & $30 \mathrm{~min}$ before & $30 \mathrm{~min}$ after & $\mathrm{p}$-value \\
\hline $\mathrm{A} / \mathrm{H}$ & $48.2 \pm 6$ & $48 \pm 6.5$ & NS & $44.3 \pm 8.7$ & $43.9 \pm 8$ & NS \\
\hline Minimum $\mathrm{Sa}_{\mathrm{a}} \mathrm{O}_{2} \quad \%$ & $68 \pm 9$ & $70 \pm 8$ & NS & $72 \pm 8$ & $70 \pm 12$ & NS \\
\hline Stage 1 NREM $\%$ & $8 \pm 4$ & $7 \pm 5$ & NS & $7 \pm 5$ & $8 \pm 4$ & NS \\
\hline Stage 2 NREM \% & $79 \pm 5$ & $77 \pm 8$ & NS & $76 \pm 5$ & $80 \pm 6$ & NS \\
\hline Stage 3-4 NREM \% & $5 \pm 3$ & $6 \pm 5$ & NS & $6 \pm 6$ & $5 \pm 5$ & NS \\
\hline Stage REM \% & $7 \pm 5$ & $7 \pm 4$ & NS & $6 \pm 4$ & $7 \pm 5$ & NS \\
\hline Awakenings $\mathrm{n}$ & $1.9 \pm 1$ & $1.2 \pm 0.9$ & NS & $1.6 \pm 0.9$ & $1.9 \pm 0.8$ & NS \\
\hline $\mathrm{Ar}$ & $49.3 \pm 5.7$ & $46.3 \pm 6.1$ & NS & $45.1 \pm 9.2$ & $43.4 \pm 8.2$ & NS \\
\hline Changing body position $n$ & $6.5 \pm 1.4$ & $7.8 \pm 2.4$ & NS & $6.9 \pm 2.1$ & $7.5 \pm 2.7$ & NS \\
\hline
\end{tabular}

Values are presented as mean \pm SD. Ar: arousal events. For further definitions see legends to tables 1 and 2. 


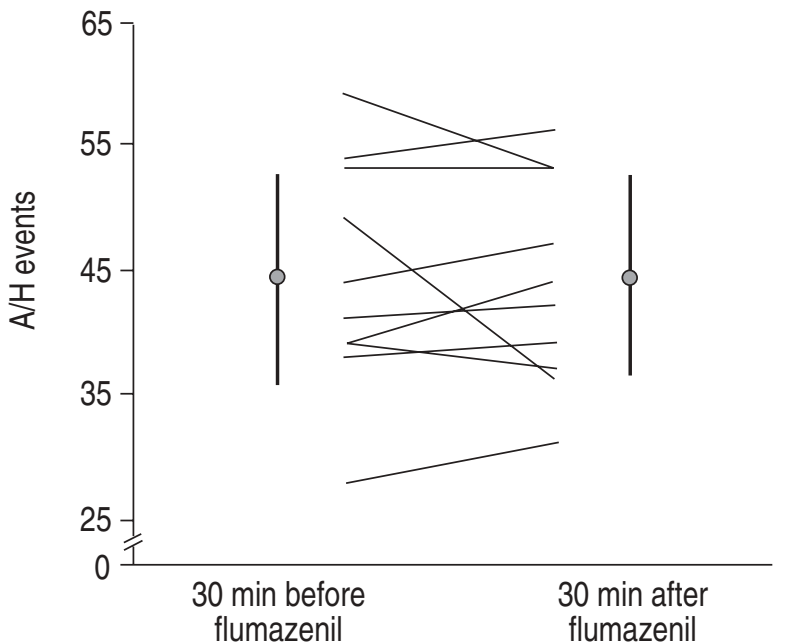

Fig. 2. - Individual apnoea/hypopnoea $(\mathrm{A} / \mathrm{H})$ events during the last $30 \mathrm{~min}$ prior to and the $30 \mathrm{~min}$ period following the administration of flumazenil. The vertical bars represent mean \pm SD for each period.

GABA-ergic tone (inhibitory neurotransmission), being transmitted by endogenous benzodiazepine-like compounds, might contribute to the pathogenesis of OSAS. If this was the case, the severity of the OSAS should decline after the administration of a benzodiazepine antagonist.

The principal finding of this study was that the benzodiazepine antagonist, flumazenil, had no consistent effect on the severity of SRBD in patients with OSAS. Furthermore, no significant change either in breathing or in sleep architecture was observed.

Due to the short half-life of flumazenil, in addition to the full night sleep study, the polysomnographic data from the period $30 \mathrm{~min}$ before and $30 \mathrm{~min}$ after the administration of flumazenil were analysed. The analysis of sleep architecture and breathing during sleep with and without flumazenil showed that flumazenil did not diminsh arousals and instability in the breathing pattern; nor did flumazenil influence body position and frequency of awakenings.

The neurobiochemical findings and the clinical therapeutic procedure used in patients with hepatic encephalopathy formed a key component to the background and the central content of the hypothesis of this study. In hepatic encephalopathy, a pathological accumulation of endogenous benzodiazepine-like compounds seems to play an important role [18, 19]. Furthermore the loss of vigilance due to hepatic encephalopathy is decreased by the benzodiazepine antagonist, flumazenil [20].

The effects of benzodiazepines on ventilation are multifactorial. The following findings have been documented experimentally: Firstly, the sensitivity of central and peripheral chemoreceptors for $\mathrm{CO}_{2}$ and $\mathrm{O}_{2}$ is reduced [14] by benzodiazepines. A suppression of the physiological arousal mechanisms to hypoxaemia and hypercapnia, and a reduction of hypoxic ventilatory response have also been shown [21]. However, a specific blunting of chemosensitivity due to diazepam or midazolam has not been proved [22]. Secondly, benzodiazepines produce an imbalance between the muscle tone of the pharynx and the diaphragmatic activity, leading to an inspiratory collapse of the upper airways and consequent obstructive events during sleep [23]. CHERNIAK [23] observed a reduced and delayed activation of the hypoglossus nerve in comparison to the phrenic nerve.

BONORA et al. [24] found that, in cats, diazepam induced a marked reduction of neuronal activity both of the hypoglossus and the recurrent laryngeal nerve. However, a simultaneous adjustable change of the phrenic nerve could not be demonstrated [24]. The underlying cause is most likely a central depression in the area of the brainstem [25, 26]. A similar, selective suppression of the activity of pharyngeal muscles is induced by the consumption of alcohol [3]. Electrophysiological studies have confirmed the pharmacological similarities of both substance classes, with both increasing the postsynaptic inhibition via the potentiation of the neurotransmitter GABA [27, 28].

Susceptible patients with underlying OSAS show an increase in frequency of apnoeas after the administration of benzodiazepines. Some case studies $[6,8]$ have found that severe sleep apnoea occurs after a therapeutic dose of benzodiazepines. Mendelson et al. [8], for example, reported a 38 year old male with a history typical of the sleep apnoea syndrome who, after a dose of $30 \mathrm{mg}$ of flunitrazepam orally, showed a significant increase in apnoea severity. In a patient with known OSAS, lifethreatening obstructive apnoeas were observed after the administration of $15 \mathrm{mg}$ of midazolam orally [6]. However, even healthy volunteers, without previously demonstrated OSAS or SRBD, may show significant obstructive respiratory events during sleep after ingestion of flunitrazepam [29]. In patients with OSAS, it could be demonstrated that the arousal threshold increased after $0.25 \mathrm{mg}$ triazolam; furthermore, the apnoea duration was slightly increased and the nadir in oxygen saturation was also modestly decreased by about 4\% [9].

There are, however, conflicting results concerning the influence of benzodiazepines on breathing in sleep. HÖIJER et al. [10] found no effect of nitrazepam in patients with mild-to-moderate sleep apnoea. Other studies in subjects without SRBD have found benzodiazepines to have no adverse effect on respiration during sleep [30-33]. The discrepant results may, in part, be due to differences in the study design and drug dosages.

The dose of flumazenil used in the present study was derived from existing results of pharmacological and toxicological studies of the drug [17, 34]. Several authors have reported that patients with pure benzodiazepines overdose require $<1 \mathrm{mg}$ flumazenil to fully reverse benzodiazepine-induced coma $[35,36]$. The basic question of our study was whether, in principle, endogenous benzodiazepine ligands play a role in the pathogenesis of OSAS and whether flumazenil has a beneficial effect on SRBD. According to its pharmacology, the short half-life of flumazenil was taken into account in the study design. The $2 \mathrm{mg}$ dose of flumazenil administered is twice as high as the above-mentioned dose needed to antagonize benzodiazepine intoxication effectively. Therefore, it is reasonable to assume that the dosage of flumazenil used in the study was adequate to antagonize possible endogenous benzodiazepine-like compounds.

It was not the aim of this study to assess the effect of flumazenil on sleep in general. For this purpose, constant plasma and cerebrospinal fluid levels would have been necessary and could be achieved by repetitive or constant i.v. administration of the drug. 
We conclude that endogenous ligands of the benzodiazepine receptor are not involved in the pathogenesis of obstructive sleep apnoea syndrome or, if they are involved, these ligands cannot be displaced by flumazenil. Therefore, therapeutic trials with flumazenil for the management of obstructive sleep apnoea syndrome do not seem to be warranted.

Acknowledgements: The authors thank H. Becker and W.E. Müller for their critical remarks and S. McNamara for the linguistic advice on the article. They are grateful to K. Krause and A. Simon for the excellent technical assistance in the sleep laboratory.

\section{References}

1. Remmers JE, DeGroot WJ, Sauerland EK, Anch AM. Pathogenesis of upper airway occlusion during sleep. $J$ Appl Physiol 1978; 44: 931-938.

2. Grunstein RR, Sullivan CE. Neural control of respiration during sleep. In: Thory MJ, ed. Handbook of Sleep Disorders. New York, Marcel Dekker, 1990; pp. 77-102.

3. Bonora M, Shields GI, Knuth SL, Barlett D Jr, St John WM. Selective depression by ethanol of upper airway respiratory motor activity in cats. Am Rev Respir Dis 1984; 130: 156-161.

4. Gulevich A, Baraldi M, Costa E. 1,4 benzodiazepines and gamma-aminobutyric acid: pharmacological and biochemical correlates. Pharmacology 1979; 19: 267-277.

5. Issa FG, Sullivan CE. Alcohol, snoring and sleep apnea. J Neurol Neurosurg Psychiatry 1982; 45: 353-359.

6. Bezel R, Russi E, Kronauer H, Mothersill I. Lebensbedrohliche Apnoe nach Midazolam bei einem Patienten mit obstruktivem Schlaf-Apnoe-Syndrom. Schweiz Med Wschr 1987; 117: 579-583.

7. Guillemineault C, Silvestri R, Mondini S, Coburn S. Aging and sleep apnea: action of benzodiazepine, acetazolamide, alcohol and sleep deprivation in a healthy elderly group. J Gerontol 1984; 39: 655-661.

8. Mendelson WB, Garnett D, Gillin, JC. Flurazepaminduced sleep apnea syndrome in a patient with insomnia and mild sleep-related respiratory changes. J Nerv Ment Dis 1981; 169: 261-264.

9. Berry RB, Kouchi K, Bower J, Prosise G, Light RW. Triazolam in patients with obstructive sleep apnea. $A m$ J Respir Crit Care Med 1995; 151: 450-454.

10. Höijer U, Hedner J, Ejnell H, Grunstein R, Odelberg E, Elam M. Nitrazepam in patients with sleep apnoea: a double-blind, placebo-controlled study. Eur Respir J 1994; 7: 2011-2015.

11. File SE, Pellow S. Intrinsic actions of benzodiazepine receptor antagonist, Ro 15-1788. Psychopharmacology 1986; 88: 1-11.

12. Hunkeler W, Möhler H, Pieri L, et al. Selective antagonists of benzodiazepines. Nature 1981; 290: 514-516.

13. Bonetti EP, Pieri I, Cumin R, et al. Benzodiazepine antagonist, Ro 15-1788: neurological and behavioral effects. Psychopharmacology 1982; 78: 8-18.

14. Hickey RF, Severinghaus JW. Regulation of breathing: drug effects. In: Hornbein TF, ed. Regulation of Breathing. New York, Marcel Dekker Inc., 1981; Part 2, pp. 1251-1312.

15. Rechtschaffen A, Kales A, eds. A manual of standardized terminology, techniques and scoring system for sleep stages of human subjects. US Dept of Health, Education and Welfare, NIH Publication No. 204, 1968; pp. 1-64.

16. American Sleep Disorders Association. EEG arousals: scoring rules and examples. Sleep 1992; 15: 173-184.

17. Weinbroum A, Halpern P, Geller E. The use of flumazenil in the management of acute drug poisoning: a review. Intensive Care Med 1991; 17: 32-38.

18. Basile AS, Hughes RD, Harrison PM, et al. Elevated brain concentration of 1,4 benzodiazepines in fulminant hepatic failure. $N$ Engl J Med 1991; 325: 473-478.

19. Olasmaa M, Rothstein JD, Guidotti A, et al. Endogenous benzodiazepine receptor ligands in human and animal hepatic encephalopathy. J Neurochem 1990; 55: 2015-2023.

20. Scollo-Lavizzari G, Steinmann E. Reversal of hepatic coma by benzodiazepine antagonist (Ro 15-1788). Lancet 1985; i: 1324.

21. Hedemark L, Kronenberg RS. Flurazepam attenuates the arousal response to $\mathrm{CO}_{2}$ during sleep in normal subjects. Am Rev Respir Dis 1983; 128: 980-983.

22. Power SJ, Morgan M, Chakrabarti MK. Carbon dioxide response curves following midazolam and diazepam. $\mathrm{Br}$ J Anaesth 1983; 55: 837-841.

23. Cherniack NS. Respiratory dysrhythmias during sleep. $N$ Engl J Med 1981; 305: 325-330.

24. Bonora M, St John WM, Bledsoe TA. Differential elevation by protriptyline and depression by diazepam of upper airway respiratory motor activity. Am Rev Respir Dis 1985; 131: 41-45.

25. Killam EK. Drug action on brainstem reticular formation. Pharmacol Rev 1962: 14: 175-223.

26. Pryzbyla AC, Wang SC. Locus on the central depressant action of diazepam. J Pharmacol Exp Ther 1968; 163 : 439-447.

27. Nestoros JN. Ethanol selectivity potentiates GABA-mediated inhibition of single feline cortical neurons. Life Sci 1980; 26: 519-523.

28. Tallman JF, Paul SM, Skolnick P, Gallager DM. Receptors for the age of anxiety: pharmacology of the benzodiazepines. Science 1980; 207: 274-281.

29. Dolly FR, Block AJ. Effect of flurazepam on sleep-disordered breathing and nocturnal oxygen desaturation in asymptomatic subjects. Am J Med 1982; 73: 239-243.

30. Bonnet $\mathrm{MH}$, Arand DL. The use of triazolam in older patients with periodic leg movements, fragmented sleep, and daytime sleepiness. J Gerontol 1990; 45: 139-149.

31. Mak KH, Wang YT, Cheong TH, Poh SC. The effect of oral midazolam and diazepam on the respiration in normal subjects. Eur Respir J 1993; 6: 42-47.

32. Roehrs T, Zorick F, Willig R, Roth T. Efficacy of reduced triazolam dose in elderly insomniacs. Neurobiol Aging 1985; 6: 293-296.

33. Timms R, Dawson A, Hajdukovic RM, Miller MM. Effect of triazolam on sleep and oxygen saturation in patients with chronic obstructive pulmonary disease. Arch Intern Med 1988; 148: 2159-2163.

34. Amrein R, Leishman B, Bentzinger C, Roncari G. Flumazenil in benzodiazepine antagonism. Med Toxicol 1987; 2: $411-429$.

35. O'Sullivan GF, Wade DN. Flumazenil in the management of acute drug overdosage with benzodiazepine and other agents. Clin Pharmacol Ther 1987; 42: 254-259.

36. Hojer T, Baehrendtz S. The effect of Flumazenil (Ro 151788 ) in the management of self-induced benzodiazepine poisoning. Acta Med Scand 1988; 224: 357-365. 